\title{
Comparing Boil and Bite with Customized Mouthguard Based on Subjective Experience of Boxers - A Pilot Study
}

\author{
Sakshi Nema ${ }^{1}$, Sneha Mantri ${ }^{2}$, Abhilasha Bhasin ${ }^{3}$ \\ ${ }^{1}$ P.G Student, Hitkarini Dental College and Hospital, Jabalpur, M.P. \\ ${ }^{2}$ Professor and Head, ${ }^{3}$ Professor, Prosthodontics and Crown and Bridge, \\ Hitkarini Dental College and Hospital, Jabalpur, M.P.
}

Corresponding Author: Sakshi Nema

\begin{abstract}
Context: Incidence of sports- related injuries are common in contact grade sports, particularly concerning the stomatognathic region. The use of intraoral mouthguards is essential in prevention, but the choice depends on the comfort and experience of the athlete.

Objective: To compare custom-made and stock (boil and bite) mouth guard in boxers cohort based on their subjective experience.

Design: Qualitative study

Setting: Academic Dental Hospital

Patients or Other Participants: The cohort of ten active boxers of 15-35 yrs. age were included from different local training institutes with details of their background characteristics without gender discrimination.

Data Collection and Analysis: Data were collected using a subjective questionnaire and analysed using SPSS version 20.0. A non-parametric test was applied.

Results: The response was calculated, and a comparison was done using Chi-Square Test for statistical significance. Customized mouth guard was found to be outstanding on all parameters except in terms of protection, where it was found equivalent to Boil and Bite.

Conclusion: Within the limitations of the study, it can be concluded that the use of customized mouth guard has significantly conquered the disadvantages of conventional mouthguard of choice, based on which the use of customized mouthguard showed be promoted.
\end{abstract}

Keywords: customised mouthguard, boil and bite mouthguard, boxers, sports injuries, sports dentistry

\section{INTRODUCTION}

As the world gets more competitive, so do the sports. In recent years the participation in sports at a very early age of life is boosted and encouraged, resulting in a rise in the number of dentofacial injuries. Dental injuries are permanent aesthetic, functional disfigurement until treated effectively, and the treatment is often costly. ${ }^{[1]}$

These injuries range from soft tissue abrasions, contusions, and lacerations to tooth avulsion, fractures, loss of one or more teeth, and other stomatognathic complications, impacting the physical, social, emotional and psychological state of the sportsperson. ${ }^{[2]}$

A survey of boxers in Poland by Emerich $\mathrm{K}$ highlighted boxing injuries being most serious among other sports because of a repeated direct blow to the face and head and reported that $36.5 \%$ have a dental injury during practice and training, ${ }^{[3]}$ which supports evidence to $33-72 \%$ injuries to boxers in their entire career by Kumamoto DM et al. ${ }^{[2]}$

Successful intervention prior to injuries can prevent the distressing situation. The roles 
of facemasks, helmets, and mouthprotectors have been successfully demonstrated in preventing sports-related injuries. According to ADA use of mouthguards/ athletic mouth protectors is recommended for the list of high-risk contact sports for orofacial injury prevention ${ }^{[4]}$

In systematic review and metaanalysis by Fernandes LM et al., dental trauma prevalence up to $7.5 \%$ to $7.75 \%$ was found in mouthguard users compared to $48.31 \%$ to $59.98 \%$ in non-users, concluding that $82 \%$ and $93 \%$ mouthguard users were less likely to suffer from dentofacial injuries. ${ }^{[5]}$

ADA/ANSI specification no.99 for Athletic Mouth protectors divides it as per specifications into ${ }^{[6]}$

\section{Type I. Stock}

\section{Type II. Mouth-formed}

Class 1. Thermoplastic

Class 2. Chemical setting

\section{Type III. Custom}

Class 1. Vacuum-formed

Class 2. Model-formed

The mouthguard absorbs the energy of the blow. It holds soft tissues apart from teeth, thereby reducing risk of soft tissue injuries. The impact of the direct blow is prevented by cushioning effect of mouthguard, reducing fracture and dislocation of jaw and condyle. ${ }^{[7]}$

Most athletes appreciate protection provided by mouthguard but have poor compliance towards it. Compliance is a critical factor in reducing the incidence of trauma while sporting, which is directly related to comfort and fit. Thus, it determines the enthusiasm and acceptance to use by the of athletes.

There have been various materials that are being used in fabricating mouthguards as per American College of Prosthodontist. ${ }^{[8]}$ Different sports call for the use of different types of material based on the nature of sports i.e. heavy-contact, semi-contact, limited contact, and noncontact as well as depending on the risk of orofacial injury i.e., high risk, moderate risk, and low risk.

A handful of studies are available internationally comparing boil and bite mouthguards with customized mouthguards regarding their use, and effect on the functioning of oral cavity, ${ }^{[9-10]}$ comfort and wearability, ${ }^{[11]}$ performance, ${ }^{[12]}$ effectiveness in the prevention of injuries, [13-14] shock absorption capacity, ${ }^{[15-16]}$ compliance of wearing, ${ }^{[17]}$ he physiological effect of wearing, ${ }^{[18]}$ factor for discontinuation. ${ }^{[19]}$ Some or all of them focused on heterogeneous sports altogether.

$$
\text { Indian literature drought }
$$

documentation related to in vivo research of mouthguard for athletes. A survey conducted on athletes involved in boxing in Jabalpur district of Madhya Pradesh state in India revealed $44 \%$ of orofacial trauma during boxing, $69 \%$ only new about boil and bite type of mouthguard, $58 \%$ of them belonged to lower socioeconomic status, although almost $100 \%$ awareness prevailed towards the use of mouthguard but there was lack of knowledge regarding customized mouthguard. ${ }^{[20]}$

Thus, the objective of our present clinical study was to compare boil and bite and customized triple layered sports guard that were used by the boxers for four months/each type, through a subjective questionnaire-based survey. An effort is made to encourage the use of a mouthguard in boxing sports.

The Null hypothesis $\left(\mathrm{H}_{0}\right)$ states there is no difference between the customized three-layered mouthguard and the standard boil and bite mouthguard.

The Alternative hypothesis $\left(\mathrm{H}_{1}\right)$ states that there is a significant difference between the customized three-layered mouthguard and the standard boil and bite mouthguard.

\section{MATERIAL AND METHODS}

Different boxing training centers of Jabalpur district were approached and ten boxing athletes who were active in game of age 15-35 yrs. were recruited for the study. 
Details of their years of boxing experience and background characteristics were recorded.

The study design was explained to the patient and consent was obtained on the consent form. The study was proceeded after getting clearance from the institutional ethical committee.

Self-adapted standard boil and bite mouthguard, Gum shield single (Apex Sporting Cooperation Jalandhar, India) were purchased from a local sporting goods store and were provided to the participants. They were asked to adapt the mouthguards themselves, as it is self-adaptable. (Fig 1) ${ }^{[11]}$

Maxillary and mandibular alginate impression is made and inspected for proper coverage. ${ }^{[8]}$ Wax bite records in maximum intercuspation position were taken. The impression was disinfected and poured with high-strength stone (Gyprock dental stone type IV) to produce models. The following are sent to laboratory for fabrication of customized mouthguard.

The Playsafe triple sheet (EVA+ Cyclo-Olefin Co-polymer (COC)+EVA) of thickness $5.5 \mathrm{~mm}$ was used for fabrication using Erkodent 3-D thermoforming machine, as per the manual of fabrication. [21] Finally, mouthguard is checked for fulfilling basic requirements, to be protective and effectively worn by the patient as per American College of Prosthodontics, ${ }^{[8]}$ and is labelled with name of boxer and delivered to the individual with necessary occlusal corrections (if required) at the time of insertion. (Fig 2)

The athletes wore each mouthguard for 4 months during their practice sessions and games. At the end of the 4-month period, questionnaire was administered to evaluate subjective experience after use. The filled questionnaires were collected for evaluation of survey response. (Fig 3 and 4)

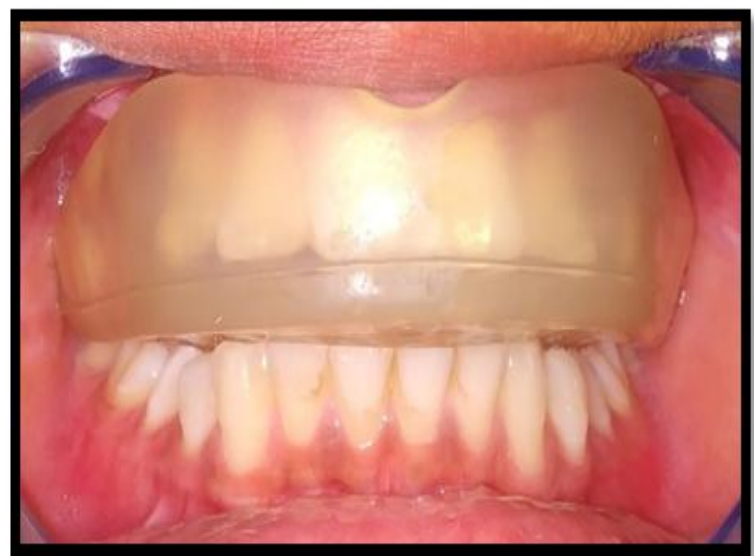

Fig 1: Post-insertion of Boil and Bite mouthguards

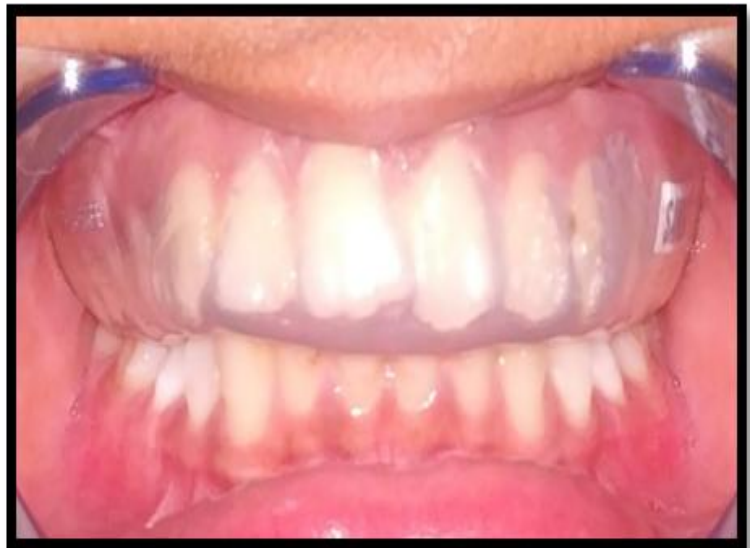

Fig 2: Post-insertion of Customized mouthguard

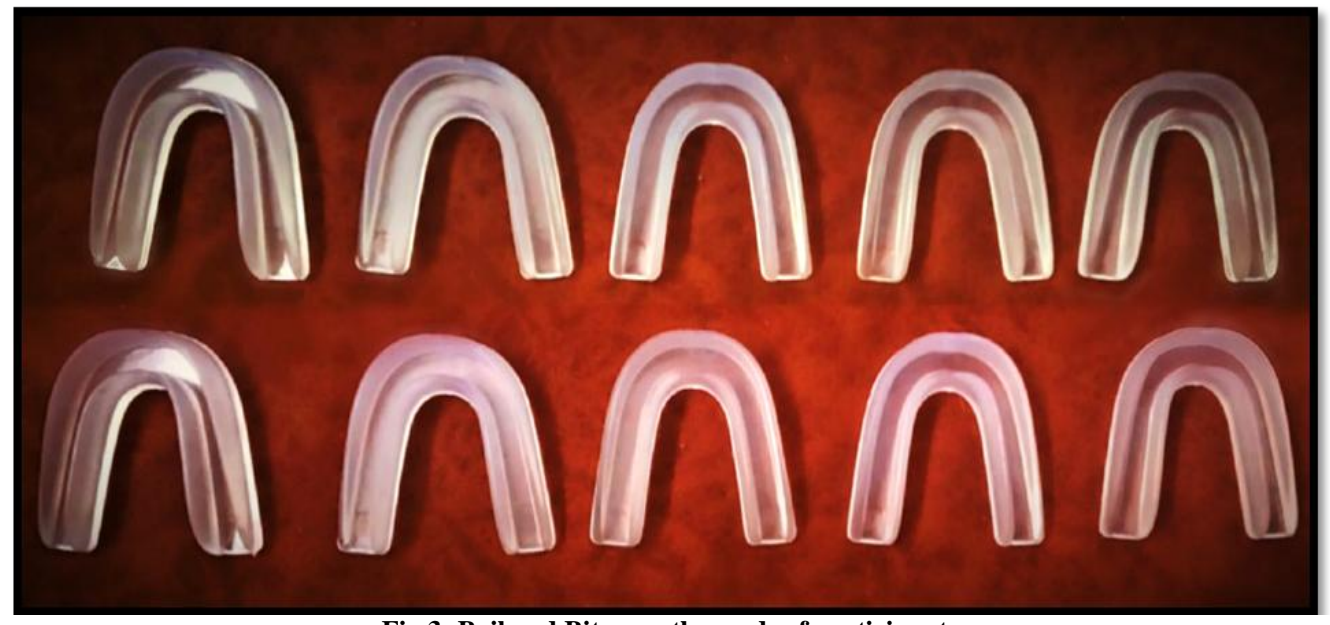

Fig 3: Boil and Bite mouthguards of participants 


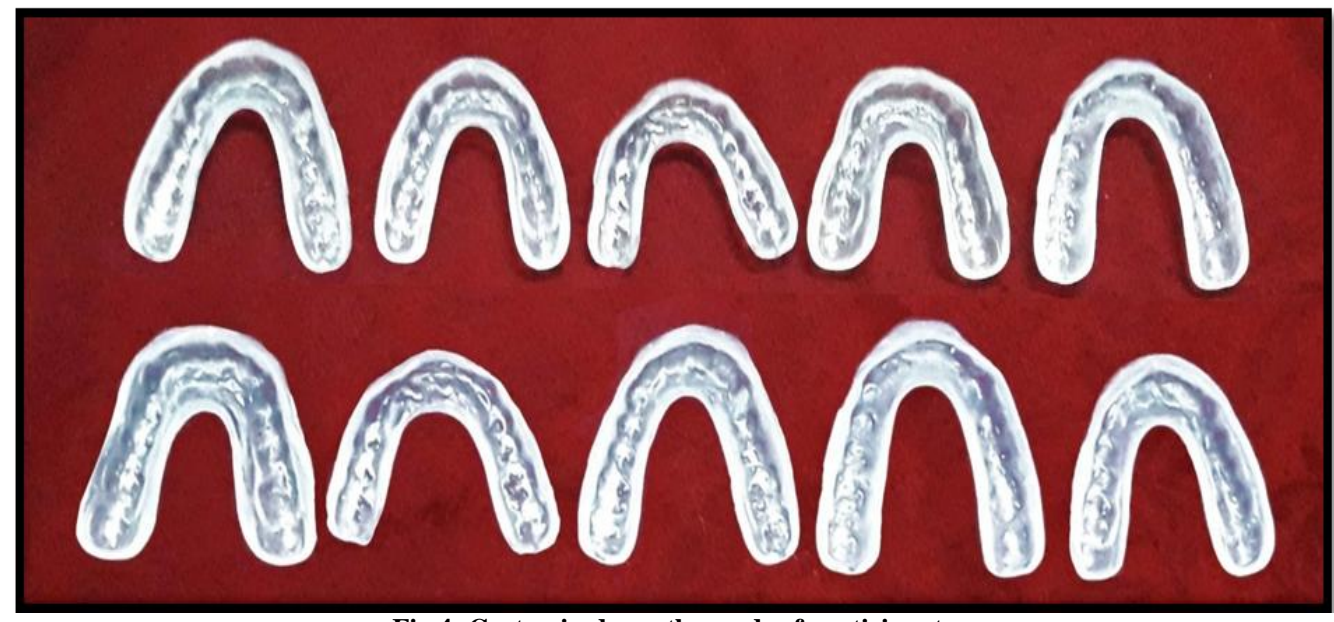

Fig 4: Customised mouthguards of participants

\section{Statistical analysis}

The obtained data was compiled and entered into a spreadsheet computer program (Microsoft Excel 2007) and then exported to the data editor page of SPSS version 20.0 (SPSS Inc., Chicago, Illinois, USA). Statistical analysis was performed using Chi-square test and level of significance was set 0.05 .

\section{RESULTS}

All the participants under study successfully completed the questionnaire survey. Results are depicted in tabular and graphical format (Table1,2,3 and Graph $1,2)$.

Table 1 represents retention and overall comfort after use of mouthguard. All the participants $(100 \%)$ were very satisfied with retention and very comfortable after using customised mouthguard whereas, $90 \%$ of boil and bite users experienced average satisfaction, and $100 \%$ had average comfort.

Table 2 represents breathing difficulty, speech difficulty and mucosal irritation and soreness after use of mouthguard. None of the athlete experienced speech and breathing difficulty while using customised mouthguard but 90\% rarely experienced mucosal irritation. On the other hand, boil and bite users often encountered speech and breathing difficulties were as $50 \%$ athletes sometimes experienced mucosal irritation.

Table 3 represents hinderance in performance and safety from repeated injury after use of mouthguard. None of the athlete experienced hinderance in performance while using customised mouthguard while $60 \%$ of athletes agreed that boil and bite hindered their performance level. There was no significant difference in the level of protection among the two types.

Graph 1 represented propensity to gag and showed increased gagging in $40 \%$ athletes while using boil and bite, and none of the athletes experienced gagging with customised mouthguard.

Graph 2 represented change in salivary flow and showed no change with customised mouthguard, and increased flow in $90 \%$ athletes while using boil and bite.

Table-1

\begin{tabular}{|c|c|c|c|c|c|c|c|}
\hline \multirow[b]{2}{*}{ Groups } & \multicolumn{5}{|c|}{ Q-How retentive was the mouthguard? } & \multirow[b]{2}{*}{$\begin{array}{l}\text { Total } \\
\text { N }(\%)\end{array}$} & \multirow[b]{2}{*}{ p-value } \\
\hline & $\begin{array}{c}\text { Very satisfactory } \\
\mathbf{N}(\%)\end{array}$ & $\begin{array}{c}\text { Satisfactory } \\
\mathbf{N}(\%)\end{array}$ & $\begin{array}{c}\text { Somewhat } \\
\text { satisfactory } \mathbf{N}(\%)\end{array}$ & $\begin{array}{c}\text { Unsatisfactory } \\
\mathbf{N}(\%)\end{array}$ & $\begin{array}{c}\text { Not at all } \\
\text { satisfactory } \mathbf{N}(\%)\end{array}$ & & \\
\hline Bite mouthguard & 0 & $1(10)$ & $9(90)$ & 0 & 0 & $10(100)$ & \multirow{3}{*}{$0.001^{* *}$} \\
\hline $\begin{array}{l}\text { Customised } \\
\text { mouthguard }\end{array}$ & $10(100)$ & 0 & 0 & 0 & 0 & $10(100)$ & \\
\hline Total & $10(50)$ & $1(5)$ & $9(45)$ & 0 & 0 & $20(100)$ & \\
\hline \multicolumn{8}{|c|}{ Q-Overall Comfort } \\
\hline Bite mouthguard & 0 & 0 & $10(100)$ & 0 & 0 & $10(100)$ & \multirow[b]{2}{*}{$0.001^{* *}$} \\
\hline $\begin{array}{l}\text { Customised } \\
\text { mouthguard }\end{array}$ & $10(100)$ & 0 & 0 & 0 & 0 & $10(100)$ & \\
\hline Total & 10(50) & $\mathbf{0}$ & $10(50)$ & $\mathbf{0}$ & 0 & $20(100)$ & \\
\hline
\end{tabular}


Sakshi Nema et.al. Comparing boil and bite with customized mouthguard based on subjective experience of boxers-a pilot study

Table-2

\begin{tabular}{|c|c|c|c|c|c|c|c|}
\hline \multirow[b]{2}{*}{ Groups } & \multicolumn{5}{|c|}{ Q- Have you experienced breathing difficulties? } & \multirow[b]{2}{*}{$\begin{array}{l}\text { Total } \\
\mathbf{N}(\%) \\
\end{array}$} & \multirow[b]{2}{*}{ p-value } \\
\hline & $\begin{array}{l}\text { Never } \\
\mathbf{N}(\%)\end{array}$ & $\begin{array}{l}\text { Rarely } \\
\text { N }(\%)\end{array}$ & $\begin{array}{c}\text { Sometimes } \\
\mathbf{N}(\%)\end{array}$ & $\begin{array}{l}\text { Often } \\
\text { N (\%) }\end{array}$ & $\begin{array}{c}\text { Too often } \\
\mathbf{N}(\%)\end{array}$ & & \\
\hline Bite mouthguard & 0 & 0 & $2(20)$ & $4(40)$ & $4(40)$ & $10(100)$ & \multirow{3}{*}{$0.001^{* *}$} \\
\hline Customised mouthguard & $10(100)$ & 0 & 0 & 0 & 0 & $10(100)$ & \\
\hline Total & $10(50)$ & 0 & $2(10)$ & $4(20)$ & $4(20)$ & $20(100)$ & \\
\hline \multicolumn{8}{|c|}{ Q- Have you experienced speech difficulties? } \\
\hline Bite mouthguard & 0 & 0 & 0 & $4(40)$ & $6(60)$ & $10(100)$ & \multirow{3}{*}{$0.001^{* *}$} \\
\hline Customised mouthguard & $10(100)$ & 0 & 0 & 0 & 0 & $10(100)$ & \\
\hline Total & $10(50)$ & 0 & 0 & $4(20)$ & $6(30)$ & $20(100)$ & \\
\hline \multicolumn{8}{|c|}{ Q-Have you encountered mucosal irritation or soreness? } \\
\hline Bite mouthguard & 0 & $5(50)$ & $5(50)$ & 0 & 0 & $10(100)$ & \multirow[t]{2}{*}{$0.028^{*}$} \\
\hline Customised mouthguard & $1(10)$ & $9(90)$ & 0 & 0 & 0 & $10(100)$ & \\
\hline Total & 1(5) & 14(70) & $5(25)$ & $\mathbf{0}$ & $\mathbf{0}$ & $20(100)$ & \\
\hline
\end{tabular}

Test applied: Chi square test; ${ }^{* *} \mathrm{p} \leq 0.001$ (highly significant) and ${ }^{*} \mathrm{p} \leq 0.05$ (significant)

Table-3

\begin{tabular}{|c|c|c|c|c|c|c|c|}
\hline \multirow[t]{2}{*}{ Groups } & \multicolumn{5}{|c|}{ Q- Safe in reducing risk of repeated injury? } & \multirow{2}{*}{$\begin{array}{c}\text { Total } \\
\mathbf{N}(\%)\end{array}$} & \multirow[t]{2}{*}{ p-value } \\
\hline & $\begin{array}{c}\text { Strongly agree } \\
\mathbf{N}(\%)\end{array}$ & $\begin{array}{l}\text { Agree } \\
\mathrm{N}(\%)\end{array}$ & $\begin{array}{l}\text { Neutral } \\
\mathbf{N}(\%)\end{array}$ & $\begin{array}{c}\text { Disagree } \\
(\mathrm{N} \%)\end{array}$ & $\begin{array}{c}\text { Strongly disagree } \\
\mathbf{N}(\%)\end{array}$ & & \\
\hline Bite mouthguard & $5(50)$ & $2(20)$ & 0 & $2(20)$ & $1(10)$ & $10(100)$ & \multirow{3}{*}{0.083} \\
\hline Customised mouthguard & $10(100)$ & 0 & 0 & 0 & 0 & $10(100)$ & \\
\hline Total & $15(75)$ & $2(10)$ & 0 & $2(10)$ & $1(5)$ & $20(100)$ & \\
\hline \multicolumn{8}{|c|}{ Q-Any hinderance in your performance? } \\
\hline Bite mouthguard & 0 & $4(40)$ & 0 & $6(60)$ & 0 & $10(100)$ & \multirow[b]{2}{*}{$0.011^{*}$} \\
\hline Customised mouthguard & $10(100)$ & 0 & 0 & 0 & 0 & $10(100)$ & \\
\hline Total & $10(50)$ & $4(20)$ & $\mathbf{0}$ & $6(30)$ & 0 & $20(100)$ & \\
\hline
\end{tabular}

Test applied: Chi square test; $\mathrm{p}>0.05$ (non significant) and ${ }^{*} \mathrm{p} \leq 0.05$ (significant)

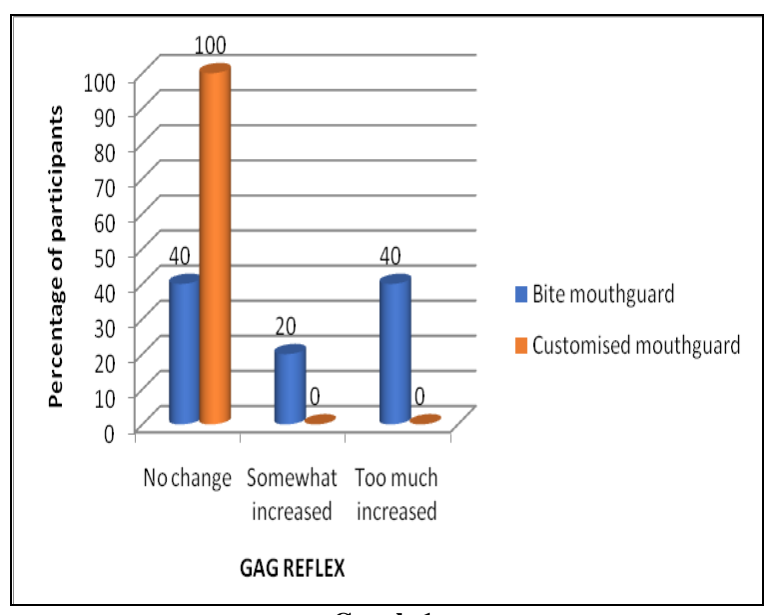

Graph-1

Test applied: Chi square test; ${ }^{*} \mathrm{p} \leq 0.05$ (significant)

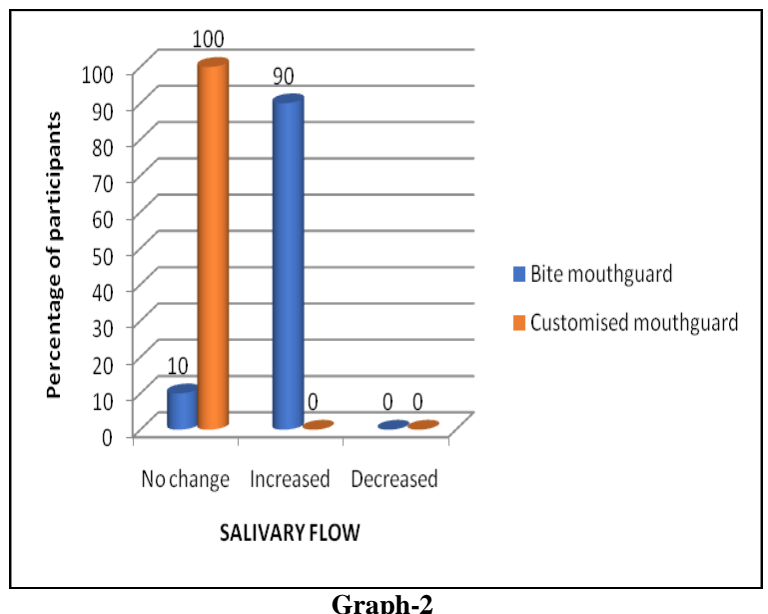

Test applied: Chi square test; ${ }^{*} \mathrm{p} \leq 0.05$ (significant)

\section{DISCUSSION}

The use of mouthguards has long been recognized as an effective and significant way of reducing the incidence of sports related orofacial injuries. Its use has been recommended in over 29 sports/ exercise activities by American Dental Association and boxing is among them. Mouthguards have proven the ability to protect soft tissues, and hard tissues by shock absorption property.

As per ADA, EVA is the most commonly used material for the conventional boil and bite mouthguard whereas, customized mouthguard has different materials for fabrication. Most frequently used is dual laminated material of outer hard and inner softer material used for customized. ${ }^{[8]}$

Therefore, in the present study on the boxing cohort of ten, subjective experience of the most commonly used boil and bite material's mouthguard is compared with customized triple-layered Playsafe Triple mouthguard with central hard and inner and outer softer material fabricated under American college of prosthodontics guidelines and with the sheet thickness of $5.5 \mathrm{~mm} .{ }^{[8]}$ 
The study was carried out for four months following the use of each mouthguard, respectively. Frequency of usage was marked 'too often' for both the mouthguard, which shows significant days of usage of mouthguard by the athletes. Results were equivalent for both the types in terms of frequency. An identical result was observed by Gawlak D et al [9] were participants used mouth protectors regularly for approximately $1.5-2$ hours during training sessions.

A study by Matalon $\mathrm{V}$ et al [22] reported $31.9 \%$ of occasional users of mouthguards in his study. Only $15.9 \%$ used it frequently during the $1^{\text {st }}$ month and then stopped whereas, $23.2 \%$ used it only when needed, and $29 \%$ did not use it at all. In contrast, McClelland $\mathrm{C}$ et al ${ }^{[23]}$ reported a mean frequency of usage of 2.5 days/week only.

In our study since the usage was found equivalent for both the mouthguards it can be concluded that the parameters recorded in observation are well grounded.

Athletic experience in terms of retention showed customized mouthguard with the superior fit when compared to boil and bite with a loose fit.

A highly significant difference was observed, similar to the previous studies by Deyoung A et al, ${ }^{[11]}$ Brionnet et al. ${ }^{[24]}$ They considered customized mouthguards to be superior to stock and mouth-formed mouthguards because of their superior adaptation and retention and in turn they are more likely to be acceptable by athletes.

In terms of comfort, while using mouthguard, boil and bite showed significantly higher discomfort than customised with little to no discomfort. Similar conclusions were reported by Duddy et al ${ }^{[26]}$ where $44.5 \%$ of the athletes experienced discomfort with over-thecounter boil and bite (UA), compared to none by customized mouthguards (CM).

McClelland $\mathrm{C}$ et al ${ }^{[23]}$ compared an ideally designed, customized (Type A) mouthguard with a less ideally designed, boil and bite (Type B) mouthguard revealing increased discomfort with less ideal design and more comfortable to use was ideally designed mouthguard. Deyoung et al ${ }^{[11]}$ concluded customized mouthguards to be the most comfortable mouthguard of choice of the study population.

Lack of proper shape, rounded edges on labial aspect and tapered round on palatal has been observed to be the reason associated with discomfort with boil and bite, also occlusal adjustment has influence on comfort and patient acceptance. This supports and justifies the choice and comfort experienced by boxers following the use of customized mouthguard.

In terms of interference in breathing, speech, and propensity to gag, present study showed a highly significant difference between the two categories of mouthguard. It concludes boil and bite to interfere the most with breathing, speech, and in inducing gag to the athletes while use, in comparison to customized mouthguard. The experience is similar to that reported by athletes in studies of Gawlak D et $\mathrm{al}^{[9]}$, Deyoung A et al ${ }^{[11]}$, Brionnet et al. ${ }^{[24]}$

Fakhruddin KS et al ${ }^{[25]}$, in his survey, noted breathing and speech difficulties with ill-fitting generic products rather than the use of custom-made mouthguards. Duddy FA et al ${ }^{[26]}$ in his randomized controlled trial on 18 collegiate athletes, conducted ergometric tests and found no negative effect on athletic performance and strength, with a customized mouthguard compared to that of boil and bite were breathing difficulties was experienced.

Kececi $\mathrm{AD}$ et al ${ }^{[27]}$ conducted a study on taekwondo athletes to evaluate ventilatory gas exchange and maximal oxygen uptake values after using custommade mouth guards, and it showed no negative effect on their aerobic performance capacity.

Erog־lu E et al ${ }^{[28]}$ studied taekwondo athletes, which showed satisfaction with kiyapping and speaking with customized mouthguard, also reported very low degree of nauseatic feeling 
because of proper fit of the customized mouthguard, which is in accordance with the observations of the present study. Finding in contrast was observed, when bimaxillary customized mouthguards of silicon was compared to that of acrylic resin mouthguard. Both significantly induced gag in the population studied by Brionnet et al. [24] Association of bulkiness was observed with incidences of nausea, quoted by McClleland et al ${ }^{[23]}$ justifies increased gag with boil and bite.

In terms of mucosal irritation or soreness encountered during use, often irritation was experienced by the boxers while using boil and bite in comparison to no irritation for a customized mouthguard. Concluding boil and bite to be irritating to mucosa while wearing during sporting.

Similar findings are observed in study by Gawlak D et al ${ }^{[12]}$ were five different mouthguards were evaluated for their effect on the functioning of the oral cavity, out of which Plorida, a standard boil and bite mouthguard produced mucosal irritation more often than other boil and bite categories, an overall score of customized mouthguards in the study was reported better than all the other boil and bite mouthguards, under study. Likewise, participants scored higher for customized mouthguards in maintaining mucosal integrity by Deyoung A et al. ${ }^{[11]}$

Deyoung A et al ${ }^{[11]}$ and McClleland et al ${ }^{[23]}$ suggests loose fitting of boil and bite and bulk of material has been the reason for irritation of mucosa, also higher temperature was found associated with soreness and burn during manipulation. In contrast, too tight fitting of customized mouthguard might cause irritation. Our study showed findings in support of this justification. However, customized mouthguard showed significantly less irritation. This shows it to be highest in maintenance of mucosal integrity because of being properly adapted.

In the parameter of risk of repeated injury, no significant difference was observed in the level of protection among the two types of mouthguards. A similar result was observed by Deyoung $A$ et al ${ }^{[11]}$ where none of the athletes reported injury while using boil and bite and customized mouthguard during the study period concluding adequate protection level of both the types. Takeda $\mathrm{T}$ et $\mathrm{al}^{[29]}$ showed a properly fitted mouthguard has a significant role in reducing fracture and bone distortion risk.

Contrasting results were observed in a prospective study conducted on athletic trainers by Labella CR et al ${ }^{[14]}$ were no significant change in the rate of concussion and intraoral soft tissue was observed among customized mouthguard users and non-users over a one year. However, mouthguard use has a significant positive effect on the morbidity of players suggests the importance of mouthguard in prevention of orofacial injuries.

In the present study, the boxers experienced significant performance related issues whereas, customized had very little to no effect on performance. The identical finding was reported in the previous literature by Duddy et al ${ }^{[26]}$ were randomized control trial was conducted to compare two different mouthguards for their effect on strength and performance on collegiate athletes which showed no effect of the customized mouthguard (CM) and negative effect of the boil and bite (OFlowTM Max Under Armour) mouthguard on performance and strength of athletes.

A comparison of effect on power production and performance of athletes with customised, boil and bite and without mouthguard by Dunn-Lewis et al [30] concludes improved performance with customized mouthguard. Observed performance related issues with boil and bite and no hindrance in performance with customised, can be justified with the misfit, breathing and speech interference, increased salivation, improper extensions and significant discomfort associated with boil and bite in contrast to favourable comfort related factors observed with customised mouthguard as suggested by Brionnet et al, 
${ }^{[24]}$ McClleland et al. ${ }^{[23]}$ Deyoung et al, ${ }^{[11]}$ Gawlak D. ${ }^{[9-10]}$

The present study shows a significant change in the flow of saliva using boil and bite mouthguard, whereas there was little to no change experienced by the athletes when a customized mouthguard was worn by the same. The result in accordance with this study was observed in a study in Warsaw. One of the schools of sports where mouthguard fabricated with a single sheet of thermoplastic material showed neither hyposalivation nor hyper with its use owing it to its better fit and Comfort by Gawlak D et al. ${ }^{[9]}$ Other literature with similar conclusions were by Gawlak D et al, ${ }^{[10]}$ and Brionnet et al. ${ }^{[24]}$

Hypothesis testing depicts clear rejection of the null hypothesis $\left(\mathrm{H}_{0}\right)$ and acceptance of the alternative hypothesis $\left(\mathrm{H}_{1}\right)$, which concludes that customized triple-layered mouthguard was found significantly better than conventional boil and bite mouthguard within all the parameters observed under the study.

\section{CONCLUSION}

Within the limitations of this study, it can be concluded that the use of customized triple layered mouthguard showed significantly better experience of the boxers in contrast to conventionally popular boil and bite mouthguard under all categories of questions. This pilot study opens new avenues for dentist in contact sports, for research and practice in future endeavors.

\section{Acknowledgement: None}

\section{Conflict of Interest: None}

\section{Source of Funding: None}

\section{Ethical Approval: Approved}

\section{REFERENCES}

1. Sane J. Comparison of maxillofacial and dental injuries in four contact team sports: American football, bandy, basketball, and handball. Am. J. Sports Med 1988; 16:64752.

2. Kumamoto DV, Maeda Y. A literature review of sports related orofacial trauma. Gen. Dent. 2004; 52:270-81.

3. Emerich K, Gazda E. Dental trauma, prevention and knowledge concerning dental first-aid among Polish amateur boxers. Journal of Science and Medicine in Sport 2013;16: 297-30.

4. Athletic Mouthguards: Indications, Types, and Benefits. The Dentistry Today. 2005 Dec 01.

5. Fernandes LM, Neto JCL, Lima TFR, et al. The use of mouthguards and prevalence of dento-alveolar trauma among athletes: A systematic review and meta-analysis. Dent Traumatol 2019 Feb;35(1):54-72.

6. ANSI/ADA. ANSI/ADA Standard No. 99:2001 (R2013), Athletic Mouth Protectors and Materials; 2013.

7. Johnsen DC, Winters JE. Prevention of intraoral trauma in sports. Dent Clin North Am 1991; 35:657-66.

8. American College of Prosthodontists. Mouthguard Use in Sports. Position Statement. Chicago, IL: American College of Prosthodontists; 2015.

9. Gawlak D, Malara KM, Kaminski T, Łuniewska M, Nastalska EM. Comparative evaluation of custom and standard boil and bite (self-adapted) mouthguards and their effect on the functioning of the oral cavity Dent Traumatol 2016:1-5.

10. Gawlak D, Mierzwinska-Nastalska E, Manka-Malara K, Kaminski T. Comparison of usability properties of custom-made and standard self-adapted mouthguards. Dent Traumatol 2014; 30:306-11.

11. Deyoung A, Robinson E, Godwin W. Comparing comfort and wearability: custom-made vs. self-adapted mouthguards. J Am. Dent Assoc 1994; 125:1112-8.

12. Aznar L, Barbosa P, Gutierres R, de Sant'Anna GR. Individualized and Mouthformed (boil-and-bite) Mouthguards: Comparative Analysis on a Soccer Team. J Athl Enhanc. 2014; 3:1-6.

13. Chisholm DA, Black AM, PalaciosDerflingher L, Eliason PH, Schneider KJ et al. Mouthguard use in youth ice hockey and the risk of concussion: nested case-control study of 315 cases. Br J Sports Med.2020:16. 
14. Labella CR, Smith BW, Sigurdsson A. Effect of mouthguards on dental injuries and concussions in college basketball. Med Sci Sports Exerc 2002; 34:41-4

15. Bemelmanns P, Pfeiffer P. Shock absorption capacities of mouth guards in different types and thicknesses. Int J Sports Med 2001; 22:149-53.

16. Mohamed N, Grobler SR, Basson NJ, Osman Y, Mulder R. A comparative study to determine the shock absorption ability of two popular mouth guards available on the South African market. SADJ 2017; 72 :6871.

17. Raaii F, Vaidya N, Vaidya K, et al. Patterns of mouthguard utilization among atom and pee Wee minor ice hockey players: a pilot study. Clin J Sport Med 2011; 21:320-4.

18. Zupan MF, Bullinger DL, Buffington B, Koch C, Parker S. Physiological Effects of Wearing Athletic Mouth Pieces While Performing Various Exercises. Military Medicine. 2018; 183:510-15.

19. Liew AK, Abdullah D, Wan Noorina WA, Khoo S: Factors associated with mouthguard use and discontinuation among rugby players in Malaysia. Dent Traumatol 2014; 30: 461-7.

20. Mohanty N, Mantri SS, Bhat N, Bhasin A, Saha U, Singha S. "Knowledge attitude and practices of boxers regarding dental trauma prevention by mouthguards". IJDSIR 2020; 3:98-107.

21. Current version of the thermoforming manual: www.erkodent.com. February 2019.

22. Matalon V, Brin I, Moskovitz M, Ram D. Compliance of children and youngsters in the use of mouthguards. Dent Traumatol 2008; 24: 462-67.

23. McClelland C, Kinirons M, Geary L. A preliminary study of patient comfort associated with customised mouthguards. $\mathrm{Br}$ J Sports Med. 1999;33(3):186-9.
24. Brionnet JM, Roger-Leroi V, TubertJeannin S, Garson A: Rugby players' satisfaction with custom-fitted mouthguards made with different materials. Community Dent Oral Epidemiol 2001; 29: 234-8.

25. Fakhruddin KS, Lawrence HP, Kenny DJ, Locker D. Use of mouthguards among 12to 14-year-old Ontario schoolchildren. J Can Dent Assoc. 2007; 73(6):505a-505e.

26. Duddy, F. A., Weissman, J., Lee, R. A., Sr., Paranjpe, A., Johnson, J. D. and Cohenca, N.'Influence of different types of mouthguards on strength and performance of collegiate athletes: a controlledrandomized trial.' Dent Traumatol 2012; 28 : 263-67.

27. Kececi AD, Cetin C, Eroglu E, Baydar ML. Do custom-made mouth guards have negative effects on aerobic performance capacity of athletes? Dent Traumatol 2005; 21: 276-80.

28. Erog lu E, Diljin KA, Lu"tfi BM. Elite tae kwon do athletes' satisfaction with custommade mouthguards. Dent Traumatol 2006; 22: 193-97.

29. Takeda T, Ishigami K, Ogawa T, Nakajima K, Shibusawa M, Shimada A et al. Are all mouthguards the same and safe to use? The influence of occlusal supporting mouthguards in decreasing bone distortion and fractures. Dent Traumatol 2004; 20:150-56.

30. Dunn-Lewis C, Luk, H-Y, Comstock BA, Szivak TK, Hooper DR. The effects of a customized over-the-counter mouth guard on neuromuscular force and power production in trained men and women. $\mathrm{J}$ Strength Cond Res 2012; 26: 1085-93.

How to cite this article: Nema S, Mantri S, Bhasin A. Comparing boil and bite with customized mouthguard based on subjective experience of boxers- a pilot study. Int $J$ Health Sci Res. 2021; 11(7): 358-366. DOI: https://doi. org/10.52403/ijhsr.20210749 